\title{
The Origin and Meaning of Medullary (Intraxylary) Phloem in the Stems of Dicotyledons.
}

\author{
I. Cucurbitaceae.
}

BY

\section{W. C. WORSDELL.}

With ten Figures in the Text.

\section{INTRODUCTION.}

THE object of botanical investigation, in whatever department, should 1 be to determine, as far as possible, the interrelationship of the various facts which are accumulated, and arrange them accordingly; and not merely, as has for so long been the custom, to pile them in a chaotic heap. This is well exemplified in the case of the study of 'internal phloem' in dicotyledonous stems. By this time we have a large, chaotic heap of facts with regard to this remarkable structure, facts which sadly need co-ordination.

It has been discovered that this intraxylary phloem occurs in a large number of natural orders. In these different orders or groups it is seen to assume different forms. Very frequently it occurs as a continuous zone immediately within the xylem of the central cylinder on the extreme periphery of the pith; or this zone may be broken up into separate groups of phloem. Sometimes such a phloem-group is more or less closely attached to the inner side of each bundle of the central cylinder. At other times the medullary bast takes the form of numerous separate strands scattered throughout the pith. Again, all or some of these features may be combined in one and the same plant or natural order.

The writer's object in the present series of papers is to endeavour to demonstrate, in those cases where this is at all possible, the meaning and origin of the intraxylary phloem. It is high time that an attempt was made in this direction, if the brake on the wheels of the chariot of progress is not to hamper for ever our efforts to obtain a glimpse of the unity of Nature in this particular field of anatomical structure.

The writer considers that medullary phloem represents, probably in all cases, a vestigial structure, the remnant of a former system of medullary vascular bundles in which the xylem has disappeared. This has, indeed, 
been hinted at by a few writers in the past, but no serious attempt ever seems to have been made to establish the theory, or to view this peculiar anatomical feature in its true light. That the surest way of determining the nature of a structure or organ is to trace its phylogenetic origin, hardly needs demonstration.

In the case of medullary phloem an attempt to do so will be made in a few natural orders where it is not hopelessly difficult. In others, however, the structure has become so stereotyped and the intermediate stages in its evolution so utterly extinct that the task is impossible.

As the first of a series of concrete illustrations of the above thesis, the order Cucurbitaceae will be taken.

\section{HISTORICAL.}

The following notices of work on this subject represent the more salient and relevant points brought out by the various authors:

Gérard concludes, from a study of the transition from root to stem in Cucumis Melo and Cucurbita maxima, that the internal phloem is a part of the external which becomes situated on the inner face of the bundle.

Petersen, in a general paper on the occurrence of bicollateral bundles, states that 'while the outer soft bast always forms an integral part of the bundle, this is not in the same degree the case with the inner soft bast'.

He refers to a continuous series of phenomena, ranging from a ring of bicollateral bundles to a ring of normal bundles with a whole system of medullary bundles within. He found in the creeping stem of Alsomitra sarcophylla that the four larger bundles of the stem almost meet in the centre, the pith being crushed, and the intraxylary phloem replaced by cambiform tissue.

Van Tieghem found in the roots of Cucurbita with a large pith, especially the large adventitious ones, that on the medullary side of each primary and secondary collateral bundle one or several longitudinal series of pith-cells divide actively to form a phloem-bundle.

Weiss determined that all the bundles in Cucurbitaceae are leaf-traces. The phloem-bundles scattered in the pith of the stem of Cucumis perennis are branches from the phloem-bundles of the leaf-traces which have passed into the outer ring. In the petioles, where the bundles are arranged in a half-moon shape, at the point where the leaf-veins branch off from the main trace, the internal unites with the outer phloem, so that the smaller bundles are no longer bicollateral.

Fischer, in a paper on the sieve-tube system of this order, traced, in Cucurbita Pepo, the transition from hypocotyl to root structure, and found that the medullary phloem gradually died out, ending blindly below. In the female peduncle the small collateral and the phloem-strands, which are associated with the bundles of the inner of the two rings, frequently 
anastomose with the latter; after fertilization they become obliterated, and the conduction of plastic substances is thereafter carried on by the usual phloem parts.

Hérail states that the Cucurbitaceae are the only plants which have bicollateral bundles, for the development of all three parts of the bundle is identical and synchronous. He noted in Zanonia sarcophylla the occurrence of interfascicular cambium connecting the bundles of the outer and inner rings into a single ring.

Lamounette has an interesting thesis on the morphological origin of the internal phloem in Cucurbita maxima. He found that in the region between the 'heel' and the first rootlets of the young hypocotyl the external phloem had developed considerably, while the internal phloem was being separately initiated by a few divisions in the parenchyma of the pith. No communication was observed between the two. The formation of the internal is subsequent to that of the external phloem. The above applies also to Cucumis and Luffa. He concludes (not only for Cucurbitaceae but for other orders investigated) that internal phloem is an abnormal formation due to the activity of certain cells of the central conjunctive parenchyma, or is the result of the ulterior evolution of these cells; it has been acquired during evolution and then transmitted by heredity. In the cotyledon and leaf of Cucurbitaceae the internal is also of later formation than the external phloem ; it does not pertain to the procambium, but has a distinct evolution from the parenchyma. He says the term 'bicollateral ' should be abolished in view of the origin of the internal phloem. The Cucurbitaceae afford the best example of the acquired secondary dependence of the internal phloem on the bundle of the ring; its more primitive condition is as an independent bundle in the pith.

Scott and Brebner found in Thladiantha dubia that the internal phloem connects with the external in the medullary ray. In a valuable study of the course of the medullary phloem in plants generally, they found that this tissue, during the transition from stem to root, passes out and unites with the external phloem. This agrees with what has been observed in Lagenaria in the present paper.

Flot, like Lamounette, will give no quarter to the term 'bicollateral', in view of the fact that the internal phloem arises independently from the perimedullary zone.

Baranetzky found in the stem of Rhynchocarpa dissecta that an inverted medullary collateral bundle which ran through one internode and part of another, was separated from the bundle of the ring by two or three layers of medullary parenchyma. Some only of the medullary bundles possessed xylem, and this usually died out in some region of the internode in following the bundle either upwards or downwards.

In Bryonia dioica and Zehneria suavis the same facts with regard 
to medullary collateral bundles were noted. In the node the xylem of the medullary bundles unites with that of the ring.

He says: "The phloem-bundles situated on the inner edges of the normal vascular bundles of these plants [Cucurbitaceae] are structures quite analogous to the internal vascular bundles in the stems of Rumex and Rheum. The internal phloem-bundles in Cucurbitaceae, when provided with their own wood, represent, doubtless, independent vascular bundles.' Their independence is also shown by their branching and by their passing from one normal bundle to another. He reaches this conclusion by the method of comparative histology.

He found that the differentiation of the first sieve-tubes in the internal phloem of Bryonia alba occurs much later than in the external phloem; but in the same plant their development may be much earlier. The development of the internal phloem-bundles of the Cucurbitaceae is just the same as that of the medullary bundles of Polygonaceae, \&c.

'The appearance of internal bundles in Dicotyledons should be regarded not as an anomaly in this type, but rather as the ulterior development and perfectioning thereof.' He regards it as an evolutionary development and cites its occurrence in some Gamopetalae in support of the idea.

Wallace studied the stem structure of Actinostemma biglandulosa, in which he found that the bundles are primarily collateral and remain so until after a considerable quantity of secondary tissue is formed. Two of the five inner bundles are very small, and at first possess phloem only; later on they acquire xylem, and still later become bicollateral like all the larger bundles of the two rings. Medullary phloem does not arise simultaneously in relation to all the ten bundles of the internode: the three large inner ones first acquire it, then the larger of the two inner bundles, next, those of the outer ring, and finally the remaining inner bundle. The wood of the normal bundle becomes surrounded by phloem. Medullary phloem does not accompany the leaf-traces into the leaf. The older petiole has collateral bundles.

Pitard found in Cucurbita Pepo tertiary phloem-strands in the rays of the stem at the edge of the wood; they are connected by branches with the internal-phloem groups of the bundles.

Faber, after tracing the development of the stem-bundles of Cucurbita $P e p o$, concluded that the internal phloem arises very early at the growing point; he found that the inner and outer phloem already existed before any vessels were formed. The sieve-tubes of the inner phloem arise from the same procambial strand as the rest of the bundle. He could discover no difference, either in the development or structure, between the outer and the inner phloem. The development of both is centripetal, i. e. towards the protoxylem. In one bundle only did he see two small xylem-elements formed from the cambium attached to the inner phloem, He says : 'It is 
merely a matter of terminology as to whether such a bundle (the bicollateral) must be regarded as two bundles lying side by side, of which one has developed phloem only, or whether the bundle must be called bicollateral; the nature of the bundle is not thereby changed. I do not see why it should not be called bicollateral, as this better expresses the single character of the strand; the development shows that the second phloem belongs to the normal bundle.'

Col states that their masked origin and rapidity of formation has led to the Cucurbitaceous bundles being passed as bicollateral.

\section{ORIGINAL OBSERVATIONS.}

\section{Preliminary Remarks.}

As a result of his previous anatomical investigations in other plants, the writer has long been convinced that, in order to discover data which may throw light on the origin and meaning of an anatomical structure of doubtful interpretation occurring in the vegetative shoot, it is generally useless to study this latter from the point of view of its developmental data, whether culled from the seedling stem (either in its epi- or hypocotyledonary regions) or from the apical meristem of the adult stem. For these data are likely to throw a minimum of light, or none at all, on the nature of a doubtful structure; on the contrary, they are often very misleading. ${ }^{1}$

The conviction, on the other hand, was reached that a far more useful mine of information lay in a study of the mature stem, and especially of the more conservative organs of the plant, such as the peduncle and the various appendages of the reproductive axis, as also the foliageleaf. These organs, having undergone less modification in the course of evolution of the plant as a whole, are likely to exhibit in their structure more ancestral features, and to reveal the particular character, whose morphological value it is desired to estimate, in a form nearer to that from which it originally sprang than can possibly be the case in the vegetative axis.

All these conclusions, previously arrived at, have been confirmed as a result of endeavours to throw light on the origin of the internal phloem in Cucurbitaceae, as will be seen from what will now be brought forward. In one or two cases, however, it will be noted that a study of the vegetative stem affords most of the necessary data, as in Acanthosicyos and Ecballium. Brief accounts of seedling structure are given in one or two instances, more for the sake of completeness than anything else.

1 Hérail's reliance on the position and mode of ontogeny of the internal phloem is, from the morphological view-point, entirely useless. 


\section{Lagenaria vulgaris.}

\section{Seedling:}

In the hypocotyl occur six bundles, having the usual bicollateral structure, surrounding a central lacuna. The transition from stem to root structure takes place below the 'heel', approximately in the region where the first lateral roots are given off. In tracing the structure downwards by means of a series of transverse sections, the internal ${ }^{1}$ phloemgroups pass outwards and unite with the outer phloem-groups immediately before the transition to root-structure occurs, and therefore just before the junction of the lateral roots. As each phloem-strand passes out it revolves on its axis through $\mathrm{I} 80^{\circ}$. The phloem-strands do not all pass out exactly at the same level. When two strands occur opposite the protoxylem of a single bundle, they pass out on opposite sides of the latter. A fairly wide pith is present even after root-structure is formed.

The fate of the internal phloem-groups is thus very different from that of those in the hypocotyl of Cucurbita Pepo, according to Fischer's data, and in Cucurbita maxima, according to Lamounette.

From such developmental facts as have just been given Gérard arrived at (what will be seen to be later) his erroneous conclusions.

There is, however, one developmental feature of some importance. Various observers, besides the present writer, have noted that the internal phloem arises at a later period than does the external phloem. It is commonly found that vestigial structures arise later in the ontogeny than is the case with other parts of the tissue-plexus. This fact would tend to indicate, therefore, that the internal phloem is a vestigial structure. As far as this goes some little clue has been gained from a study of the ontogeny. However, Faber's observations (see above) point in exactly the opposite direction.

\section{L. clavata.}

\section{Stem.}

The zone of sclerotic fibres, which is present in all Cucurbitaceous stems, always marks the limit of the central cylinder. This is an important character. Exactly the same is true for most, if not all, Monocotyledonous stems.

In this plant, immediately within the sclerotic ring, occur great numbers of rudimentary phloem-strands.

The central cylinder consists, as in so many Cucurbitaceae, of two circles of bundles. At the sides of the bundles of the inner ring, or, in

1 The term 'internal phloem' will, in the following pages, always be applied to the phloemstrand which is attached to the ventral or inner side of the 'bicollateral' bundle of the cylinder. To all other phloem-strands occurring in the pith or the embouchement of the rays the term 'medullary phloem' will be given. These distinctive terms are for purposes of clear description. 
other cases, nearly half-way between the two rings, are smaller bundles possessing a very small amount of xylem. One of these bundles, as seen in a transverse section, taken near the node, had several xylem elements attached to the outer ${ }^{1}$ side of its internal phloem.

At the side of one of the bundles of the inner ring or series was seen a small isolated phloem-strand. This fact is important: it shows the occurrence of phloem-strands which represent independent bundles; for this strand is obviously homologous with a small bundle, possessing a small amount of xylem, which was described in the last paragraph. It has thus, most probably, lost its xylem and is on the way to extinction.

\section{L. leucantha.}

Petiole.

Besides the cylinder of normal bundles there are three quite small bundles, one of which, occurring in the ring of large bundles, possesses a little xylem. The remaining small strands, occurring in the pith, possess phloem only; if traced higher up, one of these latter is seen to fuse with the internal phloem of one of the bundles of the ring; the other two appear to die out above. In the highest part of the petiole, where the medullary cavity occurs, there is no sign of any of the small strands. These latter evidently represent an interior system or ring of vascular bundles.

\section{L. clavata.}

\section{Peduncle.}

In the middle typical part of the organ there is a central pith-cavity surrounded by an irregular, sinuous ring of bicollateral bundles, evidently formed by the radial congestion of two rings. A portion of one of the bundles has its internal phloem widely separated from the xylem and from the internal phloem of the major portion of the bundle; this medullary phloem-strand is thus quasi-independent. At the side of one of the ring-bundles, near the inner embouchement of the ray, is a very small normally-orientated vascular bundle. At the inner embouchement of another ray, and alongside the internal-phloem group of the adjoining ring-bundle, is a very small inverted vascular bundle. Its position and appearance suggest that it represents a fellow-strand of the internal phloem of the ring-bundle. This is supported by the fact that, attached to the outer side of the internal phloem of two or three of the ring-bundles, are from one to a ferw xylem elements. This is due to the fusion, at least in

1 Wherever this term is used in the same connexion it has reference to the parts of the organas a whole, not to those of the individual bundle. 
some cases, of a small inverted bundle with the internal-phloem group. This phenomenon will be referred to hereafter in the case of another plant, and will then be commented on, as it is a fact of first importance.

In the basal region of the peduncle the ring of bundles is quite normal, and none of the small bundles occur.

\section{Cucurbita Pepo.}

\section{Seedling.}

The transition to root-structure occurs just below the 'heel'. As the protoxylem of each bundle divides and turns outwards, portions of the internal-phloem strand also branch off on either side and pass out to unite with the external phloem; this is easily observed, as the albuminous cells are particularly abundant and well-defined. This 'passing out' of the internal phloem is deduced from the fact that at this level connexions between the internal and external phloem occur, which phenomenon is not present above and below this region, and that the internal phloem decreases greatly in amount at a lower level. There would not occur the abovementioned connexions of the external with the internal phloem if the latter merely died out in situ. The connexions, consisting of groups of albuminous cells in the rays between the bundles, therefore indicate a passing out of a portion of the internal phloem. Now, it is an interesting fact that not all the internal phloem passes out. The protoxylems revolve, and a contimuous cylinder of wood is formed before the latter process is complete; so that scattered elements of internal phloem are left behind and enclosed in the wide pith, and eventually die out below. The conclusions of Lamounette and Fischer are thus only very partially correct in regard to this genus. The former relied far too much on the misleading data of the ontogeny.

\section{Stem.}

In the subaerial portion, some distance beyond the yellow-coloured underground part, the cambium of the internal phloem has, in most of the bundles of the ring, developed a large amount of xylem which consists mainly of parenchyma, with vessels and fibres in some of the bundles. The phloem of these bundles is connected with that of the ring-bundles by commissural strands; the woody part of the xylem appears to die out at a lower level, to reappear again in the yellow underground portion.

In another plant, at the lowest node, a few inches above the base of the stem, where the yellow portion of the latter begins, the internalphloem groups send off branches abundantly both to the external phloem 
and to each other. The wide rays are filled with separate phloem-strands. The internal-phloem groups also give off smaller branches, pursuing a very irregular twisting course, into the pith, where small phloem-groups are seen to occur; some of these latter possess, at least during part of their course, xylem.

This structure of the node is not a haphazard one. The node is the most conservative portion of the vegetative stem. In the absence of any convincing proof of the presence of a physiological cause to account for the supernumerary medullary phloem-strands and bundles, their presence may be regarded as an ancestral trait, probably representing the vestiges of a former medullary bundle-system. The fact that they belong to the same system of strands as the ordinary internal-phloem strands of the ring-bundles, shown by their fusions therewith, is an indication that the ordinary internal-phloem strands really represent independent bundles which have, in the majority of cases, lost their xylem through degeneration.

\section{Peduncle of Male Flower.}

In the upper part one or two of the bundles of the ring have a few primary xylem elements on the pith-side of the internal phloem, which, lower down, along with a little phloem, pass off as a small medullary bundle, whose xylem, at a still lower level, dies out. In other words, a phloem-strand of the pith, if traced upwards, becomes a vascular bundle, which, at a still higher level, fuses with the internal phloem of one of the ring-bundles. This phloem-strand was not traced to its conclusion in the lower part of the peduncle ; it probably ended blindly in the pith.

\section{Peduncle of Female Flower.}

In a young peduncle examined there were seven phloem-strands situated in the pith near the bundles of the cylinder; they were about the same size as the internal-phloem strands of the latter, but quite circular in shape. Some have a smaller phloem-strand lying near them; these smaller strands also occur in the rays and pericycle, and are very numerous ; farther down they either fuse with the larger strands (internalphloem groups or medullary ones) or else die out in situ. The larger medullary strands were not followed to their ending. Some of these latter have a vessel or two attached to them, chiefly on the outer side.

In a mature peduncle bearing a fruit it was observed that in the upper region below the fruit occurred great numbers of small variously-orientated vascular bundles in the pith, nearer the margin than the centre of the latter, as also along the inner sides of the ring-bundles at the embouche- 
ment of the rays. Three of these bundles were traced downwards; from one of them, whose xylem was directed outwards, three or four minute phloem-strands became separated off, which eventually fused with an internal-phloem group. The bundle itself fused with one of two bundles lying opposite the adjoining ring-bundle, the product of fusion farther down fusing with this ring-bundle, i. e. with its internal phloem; the remaining one of the two bundles just mentioned dwindled greatly

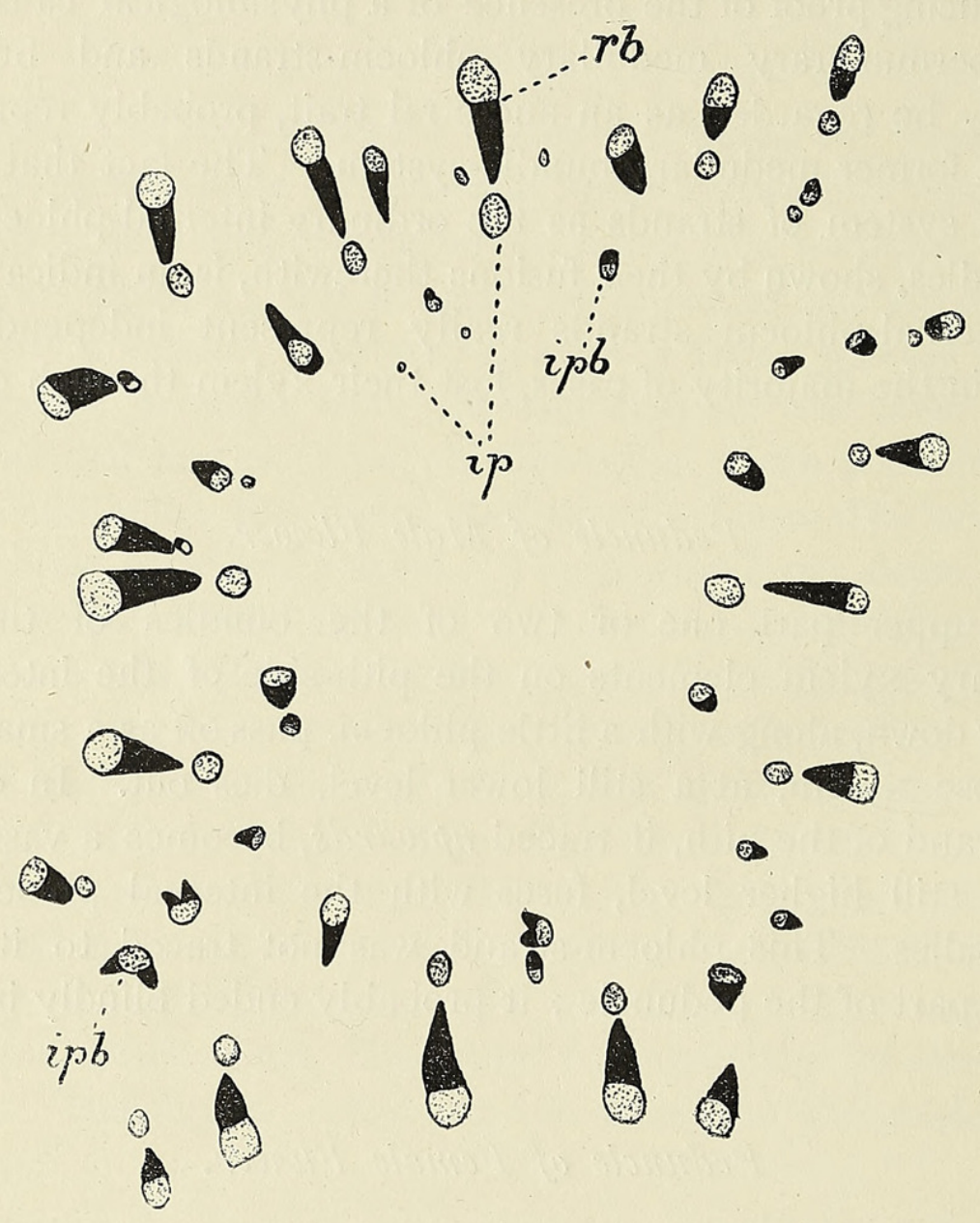

FIG. I. Cucurbita Pepo. The vascular tissue of the fruiting peduncle, in transverse section, showing scattered and independent internal-phloem strands and bundles; the latter variously orientated, and one or two with amphivasal structure. $r b$, vascular bundle of the normal ring; $i p$, internal phloem; ipb, medullary bundle or bundle of abnormal ring, homologous with 'internal phloem'. $\times$ II.

in size, and finally appeared to die out so close to the large internal-phloem group that it practically amounted to a fusion therewith.

Another small inverted medullary bundle, on being traced downwards, was seen to fuse with the internal-phloem group opposite to it; after the fusion the xylem of the former occupied a lateral position in the resulting large phloem-group; farther down it appeared embedded in the middle, remaining so as far as it was traced, so that the phenomenon occurred of an internal-phloem group with central xylem.

In another fruit-peduncle there were one or two rings of large bundles 
composing the cylinder, with here and there much smaller bundles in the pith closely adjoining them or on their sides; these small bundles are inverted collateral or amphivasal in structure. The internal phloem of the large bundles of the ring has the form of a detached, large, rounded strand encircled by a cambium which, in nearly all cases, has formed some tissue which has the characters of the xylem parenchyma of the main bundle; it is usually most greatly developed on the inner (pith) side ; in only one case was a small group of vessels seen attached to the inner side of the internal phloem ; but the soft-walled tissue formed by the cambium may be regarded as xylem. Not only are there distinct evidences of the scattered arrangement of the bundles of the cylinder, but there is also a distinct tendency in these towards amphivasal structure, for the bundle whose internal-phloem group possessed vessels was concentric, the phloem being completely encircled by the xylem; all the other bundles are very V-shaped.

The above-described fusion of a small medullary vascular bundle with an internal-phloem group leads to the conclusion that the latter represents an independent vascular bundle which has lost its xylem, for the medullary bundle becomes one with it, and the internal-phloem group becomes, at a lower level, a vascular bundle.

No case is known in any plant of a vascular bundle fusing with the outer phloem of a bundle of the cylinder. Hence the internal phloem is not the equivalent of the outer phloem, in the sense of forming a constituent part of the bundle of the ring, but must be regarded as an independent bundle of the pith. This view is again strongly supported by the facts recorded in the second fruit-peduncle: the independent character of the rounded internalphloem group, with its parenchymatous and, in some cases, woody xylem. It clearly represents an incompletely formed amphivasal vascular bundle, and is probably a vestigial structure. The bundles of the cylinder are also clearly more or less perfect or imperfect amphivasal bundles. The whole thus constitutes, in the writer's opinion, the vestige of a scattered system of bundles composed of several series or irregular rings; the internalphloem groups attached to each ring of bundles would represent always, on this view, a distinct series or ring of bundles (cf. Fig. 9).

\section{C. foetidissima (Cucumis perennis).}

Stem.

In the extreme basal region is a single bundle-ring of quite cylindrical contour and composed of about twelve bundles of various sizes and rather closely approximated, the large internal-phloem masses occupying almost the entire pith. At a higher level the number of bundles is greatly increased and the ring is no longer of cylindrical contour, but exceedingly sinuous, consisting of five arms. In the outer or pericyclic zone of the 
cylinder occur great numbers of small phloem-strands; of these some, viz. the most rudimentary, occurring immediately within the sclerotic ring, are those met with in this region in most Cucurbitaceae ; but others, representing an extension of this system, are larger, of varying size, irregularly grouped, and occurring chiefly between the protrusions of the bundle-ring. Those, however, which approximate to the ends of the latter, and thus tend to form part of the bundle-ring, possess some xylem. It is thus evident that there are transitions between the tiny phloem-strands of the extreme outer edge of the cylinder and the vascular bundles of the ring. It was not ascertained whether the tiny outer vascular bundles unite with the bundles composing the ring-protrusions or whether they die out at a higher level;

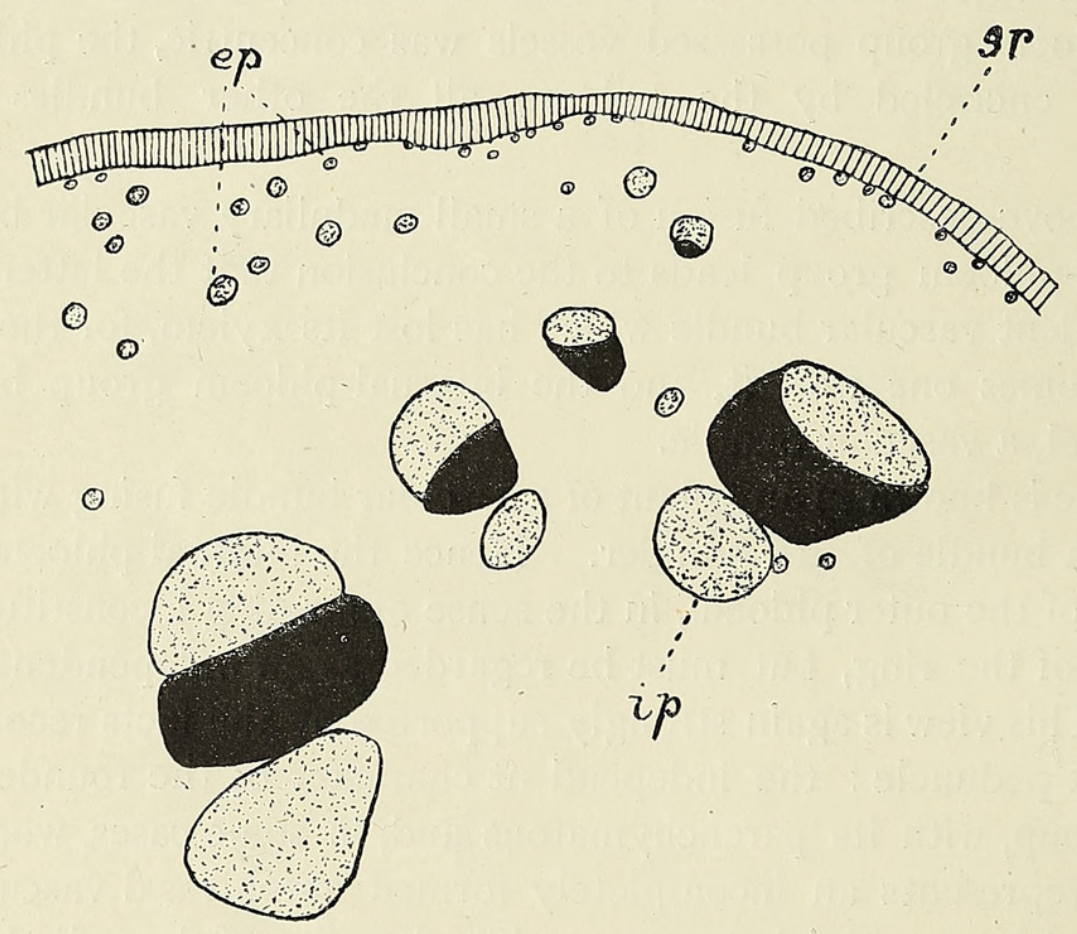

FIG. 2. Cucurbita foetidissima. Transverse section of a small portion of the central cylinder of the stem, showing a transition between the bundles of the ring and the small phloem-strands (epp) of the extreme periphery of the cylinder; these latter representing vestiges of former vascular bundles. ip, ' internal phloem'; sr, sclerotic zone. $\times 27$.

this is immaterial; it is certain, however, that the tiny phloem-strands do die out at a higher level.

We may conclude that the tiny phloem-strands and bundles described represent the vestigial remains of one or more outermost series or rings of bundles. In other words, there are in this stem clear traces of an ancestral scattered bundle-system, such as occurs in Monocotyledons. The peculiar sinuous contour of the bundle-ring, so characteristic of the Cucurbitaceae, can also be explained. It represents an attempt to condense all the rings or series into a single ring, the contour of which becomes more and more cylindrical and even and the individual bundles (or some of them) larger as the base of the stem is approached. The sclerotic ring, situated, 
as a rule, near the periphery of the stem, just as in Monocotyledons, limits as is the case in this class, the central cylinder.

In this species we thus discover in the stem the existence of vestigial remains of outer series of bundles pertaining to the original scattered system ; in the last species we found the vestiges of an inner series of bundles belonging to the same scattered system.

\section{Cucumis sativus.}

Stem.

As far down as a few millimetres or so below the point at which the green portion of the stem terminates the structure offers nothing of particular interest. But at about that level, where the stem has become very deeply lobed and fluted into six columns, each of which is traversed by a bundle, the majority of these bundles has each, in place of the ordinary internal-phloem strand, an inverted vascular bundle, ${ }^{1}$ often more than half its own size, a large amount of xylem being present, including vessels and fibres.

In another stem the external phloem is connected with the internal by ' commissural strands' which also often have a cambium and a few xylem elements formed at the flanks of the xylem of the main bundle; this latter is often quite surrounded by phloem.

It is thus in the lower part of the stem only that the internal-phloem strand is represented by a vascular bundle.

\section{C. echinophorus.}

$$
\text { Petiole. }
$$

In the typical region, where the groove occurs on the upper side, is a complete circle of bundles; but those on the median upper side opposite the groove are rudimentary, having one or two or no xylem elements and a small amount of phloem; two, at any rate, are represented by small phloem-strands only. One of the bundles near the end of what (when the ventral bundles have died out lower down) will become the arc has several xylem elements developed on the outer side of the internal phloem, forming a quite distinct and individualized inverted bundle.

\section{Cucumis Melo.}

\section{Peduncle of Fruit.}

The double series of bundles is practically constituted as a single ring. A few of the bundles have two internal-phloem strands, one behind the other in the same radial line; in one case the extra (innermost) strand

1 Solereder makes no mention of this. 
appeared to be double. These facts also strongly support the view that the internal phloem represents an independent bundle.

Two or three of the internal-phloem strands possess woody elements (vessels and fibres) on their outer side, a fact which of course rounds off the evidence, already partly supplied by the above-mentioned facts, that the internal phloem in this genus represents an independent bundle which has, for the most part, lost its xylem.

\section{Citrullus vulgaris.}

\section{Seedling.}

In the transitional region between the hypocotyl and the root the internal-phloem strands, of which each bundle may have two or three, pass out along the side of the bundle and unite with the external phloem, leaving the bundles completely free from internal phloem before the protoxylem begins to rotate.

This phenomenon, which was also noted in Lagenaria, appears to prove that the internal-phloem strand is not a constituent part of the bundle, as it moves quite independently of the latter, and at a different time, behaving, in fact, exactly like an independent medullary bundle.

\section{C. ecirrhosus.}

Stem.

This plant was collected by the writer in the Namib desert of Damaraland in I9IO. The stem is prostrate and trailing, with a structure like that of a root, for there is hardly any pith. There is a large amount of secondary

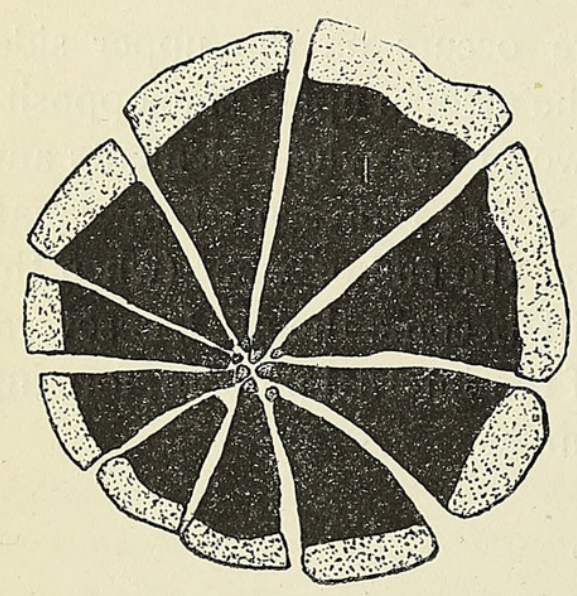

FIG. 3. Citrullus ecirrhosus. Transverse section of the ring-bundles and in. ternal-phloem strands of the stem. $\times$ II. wood, with wide-lumined vessels.

The usual internal phloem is present. The rays are wide.

The limit of the cylinder is indicated by isolated groups of fibres.

\section{Peduncle of Fruit.}

In the swollen part of this organ immediately below the attachment of the fruit is a ring of bundles possessing not nearly so much secondary wood as in the case of the stem-bundles, and enclosing a somewhat wider pith. The internalphloem strands of the stem are here
hich clearly belong to the amphivasal type, represented by vascular bundles which clearly belong to the amphivasal type,
but, in some cases, are reduced therefrom, having xylem on their outer side 
only; one or two, however, have xylem completely, or in the case of others incompletely, surrounding the phloem. The cambium entirely surrounds all the bundles. The outer portion of the xylem of these bundles abuts very closely, only separated by one to three parenchyma elements, on the protoxylem of the ring-bundle. The xylem of the amphivasal bundle consists for the most part of short fibres with rudimentary bordered pits in their walls, quite similar to those of the wood of the ring-bundle. But the elements nearest the protoxylem of the latter are rather shorter, with rather thinner lignified walls, covered with very numerous simple pits, and with very slightly oblique end-walls. All the internal bundles show a tendency to doubling, their xylem consisting of two arc-shaped strands more or less united in the tangential plane.

Here and there in the cylinder is a curious group of bundles: on one or both sides of one or more of its large bundles, a much smaller bundle of the cylinder occupies an oblique position in the angle between the large bundle of the cylinder and the internal (medullary) bundle; the latter is also somewhat obliquely placed. The explanation probably is that an attempt is here being made to merge the bundle of the cylinder and the internal (medullary) bundle into a more closely compacted and better organized whole, viz. into a large concentric (amphiphloic) bundle. ${ }^{1}$ From the morphological point of view the structure indicates the ontogenetic origin of the internal-phloem

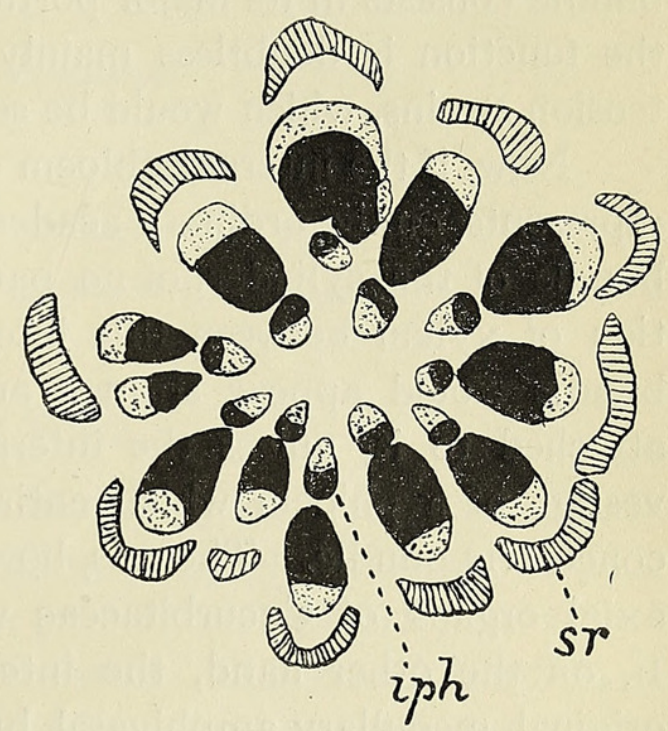

FIG. 4. Citrulhus ecirrhosus. Transverse section of central cylinder of fruiting peduncle, showing the independent internalphloem bundles. iph, 'internal phloem'; $s r$, sclerotic zone. $\times$ II. bundles from the ring-bundles, for the obliquely situated strand represents one of the former which is imperfectly separated off from one of the latter. The arc-shape of the phloem of the ring-bundle causes the oblique position of the strand above mentioned; and we can find in these facts an explanation of the inverted orientation of the internal-phloem bundles, for if we imagine the oblique strand passing further towards the pith, it would, as we know from the analogy of similar cases, revolve further on its axis so as to eventually assume an inverted position. This is, indeed, exactly what happens when the internal-phloem strands (which represent these bundles in the hypocotyl) pass inwards from the phloem of the ringbundle; the phloem-strand (imperfect bundle) revolves on its axis and on reaching the pith assumes an inverted position.

1 Cf. case of Acanthosicyos and the 'stele' of Primulaceae. 
As the basal portion of the peduncle is approached the xylem of the internal amphivasal bundles gradually becomes extinct. The inner xylem, where it is present, disappears first, to be followed eventually by the outer xylem, until, in the narrow basal part, the structure is precisely that of the vegetative stem, with internal phloem only.

At the node, representing the point of origin of the peduncle, some of the medullary bundles have well-developed outer xylem.

The occurrence of complete vascular bundles, with inverse orientation, in the place of the internal-phloem strands, in the upper part of the fruiting peduncle is probably an adaptation to meet the structural requirements arising from the attachment of a large fruit. - As the xylem of the internal bundle consists in its major portion of fibres, and exhibits very few vessels, the function is doubtless mainly a mechanical one, viz. to meet and resist tension strains, which would be severest in that part of the peduncle.

Now, if the internal phloem of the stem and lower part of the peduncle represents, on the ordinary academic view, an indissoluble constituent of the bundle of the cylinder, of no particular morphological value, the intercalation of xylem between this internal phloem and the xylem of the ringbundle would appear strange and anomalous and no meaning could be attached to it, unless the internal phloem is to be regarded as the last vestige of a phloem which entirely surrounded the xylem in an original concentric bundle. There is, however, no evidence that the bundles of the axial organs of Cucurbitaceae were originally amphiphloic in structure. If, on the other hand, the internal phloem represents the vestige of an original medullary amphivasal bundle, then the reappearance of its xylem for the purposes above described is easily understood, for the new mechanical elements are laid down in the place, so to speak, of least resistance, i.e. where they formerly existed in the axis of the ancestor, the reversion to the primitive condition being easily invoked by the stimulus of the tension-strain.

As has been mentioned above, the tendency to form large concentric amphiphloic bundles does occur, but this is not to be regarded as having a reversionary significance, for it is purely adaptational.

\section{Ecballium Elaterium.}

\section{Stem.}

In the lower part the internal phloem is replaced by large complete bundles separated some little distance from the protoxylem of the cylinder by ground tissue ; its cambium has formed a very large amount of parenchymatous tissue, mostly pertaining to the xylem, amongst which in every bundle are from one to several vessels or fibres situated on the outer side of the phloem-strand (cf. Fig. 9). 
(Intraxylary) Phloem in the Stems of Dicotyledons. I. 583

The peduncle has nothing of interest in its structure.

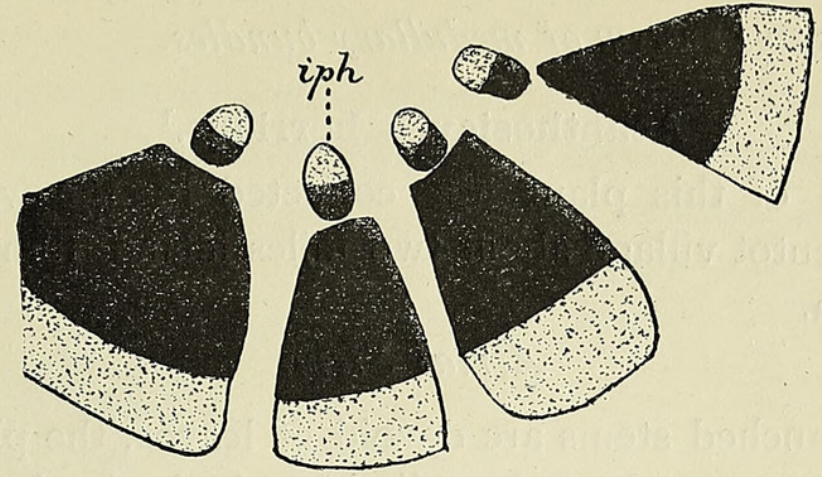

FIG. 5. Ecballium Elaterium. Transverse section of stem-base showing the independent ' internal-phloem' bundles. iph, 'internal phloem'. $\times$ II.

\section{Trichosanthes anguina.}

Stem.

Two of the bundles of the inner of the two rings or series have no internal phloem at all, nor do they possess protoxylem, so that they may represent secondary structures.

\section{Peduncle of Fruit.}

In the inner fleshy rind of the fruit are great numbers of small variously-orientated and constructed bundles, many of which are devoid of xylem. At a lower level, i. e. in the upper part of the peduncle, the vascular system consists of two rings or series of normal bicollateral bundles, and within these, in the pith, are a few bundles representing those above mentioned, which have descended from the inner rind of the fruit. One of these medullary bundles consists of a rounded phloem-strand with xylem elements situated at intervals round the greater part of its periphery; another had a little xylem on its outer side, apparently formed by a cambium ; others consisted of phloem only. At a lower level in the peduncle all these medullary bundles or phloem-groups unite with the internalphloem strands of the bundles of the inner ring; at a still lower level one of these internal-phloem strands apparently had several xylem elements in its midst, due to its fusion with a medullary bundle.

If we regard the structure as traced upwards from the base, we see the internal-phloem strands of the inner ring of bundles branching and giving rise to independent phloem-strands or vascular bundles, as the case may be, which constitute a distinct medullary system; the xylem of the vascular bundles which arise in this way is apparently differentiated either, as in the above instance, before the bundle leaves the internal phloem-strand or at a later period.

The above-described structure of the peduncle is an interesting one, for, 
inasmuch as the medullary bundles are shown as arising from the internal phloem-strands, it follows that these latter must be regarded as forming part and parcel of the same system of medullary bundles.

\section{Acanthosicyos horridus. ${ }^{1}$}

The material of this plant was collected by the writer on a sandmound at a Hottentot village about two miles inland from Walfisch Bay in South-west Africa.

\section{Aerial Stem.}

The rigid branched stems are devoid of leaves, the place of each leaf being occupied by a pair of woody cylindric stipules in the form of spines.

The cortex is very narrow. The sclerotic zone limiting the central cylinder externally has a very sinuous outline, forming a number of deep intrusions on the flanks of and around the points of which the periderm occurs. These sclerotic intrusions correspond in number to, and are opposite, the main bundles of the cylinder. In the bays between the sclerotic intrusions occur the very small bundles, one, as a rule, in each bay, of the outer ring or series of the cylinder. Each has a small internal phloem-strand which is very loosely, i.e. far from intimately, connected with the xylem. In one bay there were three small bundles, only one of which, viz. the middle one, possessed internal phloem. In the outer (cortical) bay formed by each sclerotic intrusion occurs the green assimilating tissue of the stem.

The inner (main) series of bundles of the cylinder, about sixteen or seventeen in number, are very well-developed, and each has a large, very rounded internal-phloem strand. Of these latter one to three possess xylem, consisting of vessels and fibres and a large quantity of parenchyma, on the outer side between the phloem and the protoxylem of the bundle.

There is a fairly wide pith.

\section{Subterranean Stem.}

This is very thick and woody.

The same structure is found as in the aerial stem, but there is relatively less xylem attached to the large internal phloem-strands, a fact which is probably correlated with the very large amount of wood developed in the bundles of the ring.

\section{Peduncle of Fruit.}

The fruits had at this time (April, 1910) attained a fair size (about that of a croquet-ball), but were not yet ripe.

The structure of the peduncle is, in essentials, the same as that of the aerial stem. All the internal-phloem strands have, on their outer side,

1 Marloth has written an interesting account of the habit and structure of this plant. 
a large amount of xylem, most of which is parenchymatous, but with a small group of fibres developed towards the outer side.

On the other hand, the xylem on the outer side of the internal phloem of the outer series of bundles is, in almost every bundle, much more greatly developed both as regards parenchymatous and woody elements, sometimes equalling that of the bundle itself; both the external and internal phloem

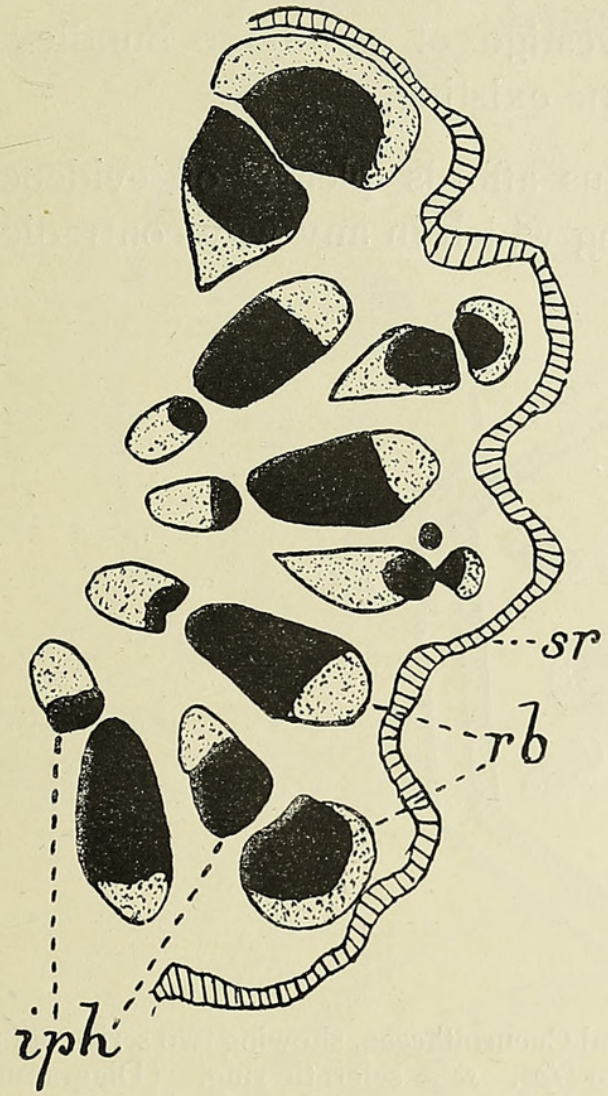

Fig. 6. Acanthosicyos horridus. Transverse section of peduncle, showing two rings or series of bundles, each with its internalphloem bundles $(i p h)$. $r b$, vascular bundle of the normal ring; $s r$, sclerotic zone. $\times I I$.

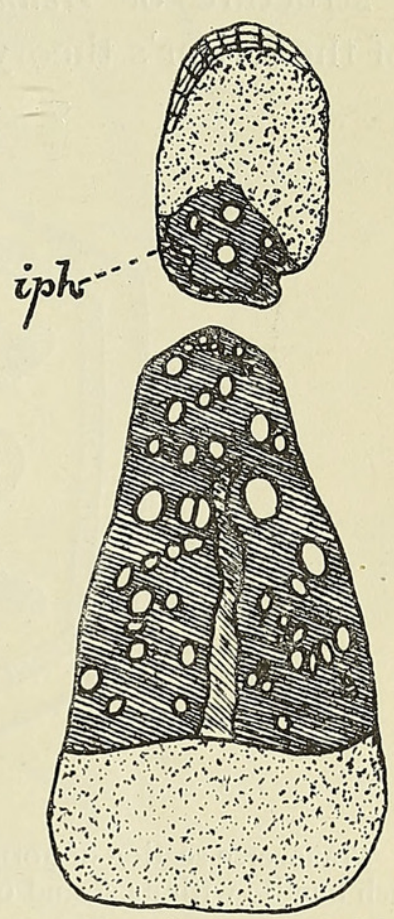

FIg. 7. Acanthosicyos horridus. 'Transverse section of a single bundle of the ring with its internal-phloem bundle (iph); the essential amphivasal structure of the latter is shown by the cambium situated on its medullary side. $\times 30$.

are very arc-shaped with the concavities, filled with the xylem, opposed to each other; the internal phloem is also much radially extended. The whole resembles a large concentric (amphiphloic) bundle incompletely built up owing to the presence of two wide rays, one on either side, representing the ground-tissue areas separating the two large vascular bundles.

\section{Stipule.}

A cylindric organ resembling a small twig in its structure.

The outer series of bundles, situated in the bays between the sclerotic intrusions, is much better developed than the inner series. The latter are more or less rudimentary, with an almost complete absence of internal 
phloem. The internal phloem of the exterior bundles is well developed and separated from the protoxylem of the bundle by two or three ground-tissue elements; this fact, and the further one that most of the internal-phloem strands have xylem elements attached to their periphery at various points, shows clearly that the internal phloem of these exterior bundles represents an independent bundle, having no morphological connexion with the bundle opposite which it occurs. These internal-phloem groups of the outer bundle-series doubtless represent the vestige of a former bundle-series occurring between the two at present alone existing.

The structure of Acanthosicyos thus affords plenty of evidence in support of the writer's theory, and nothing which in any way contradicts it.

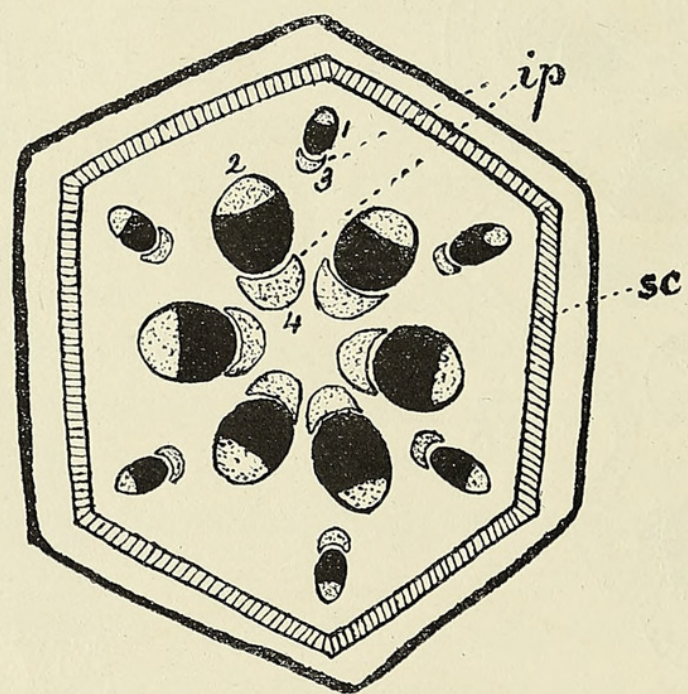

FIG. 8. Transverse section of normal stem of typical Cucurbitaceae, showing two series of bundles ( $\mathrm{I}$ and 2 ), each bundle with its strand of internal phloem $(i p) . s c=$ sclerotic ring. (Diagrammatic.)

\section{Summary AND CONClusions.}

The following are the main results of this investigation:

I. The more conservative parts of the axial configuration, viz. the peduncle, and the node of the vegetative stem, are those in which ancestral traits in the structure are most likely to have been retained.

2. What are considered to be ancestral features have been found in these regions; but also, in some cases, in the internodal region of the vegetative stem.

3. Questions and data relating to the ontogeny, such as the development of the internal phloem (or bundle) from the same desmogen strand as the bundle of the ring; or the primary or secondary (cambial) mode of development of parts of the internal-phloem bundle, are of no value for throwing light on the origin of the internal phloem (or bundle).

4. In the vegetative stem of certain members of the order, and, as a rule, in its lower part only, the internal phloem exists in the form 
of vascular bundles of which the xylem exists entirely, or for the most part, on the outer side.

5. Distinct vestiges of a medullary system of bundles, having the form sometimes of vascular bundles, sometimes of phloem-strands, have been found in the peduncle and the node of certain genera.

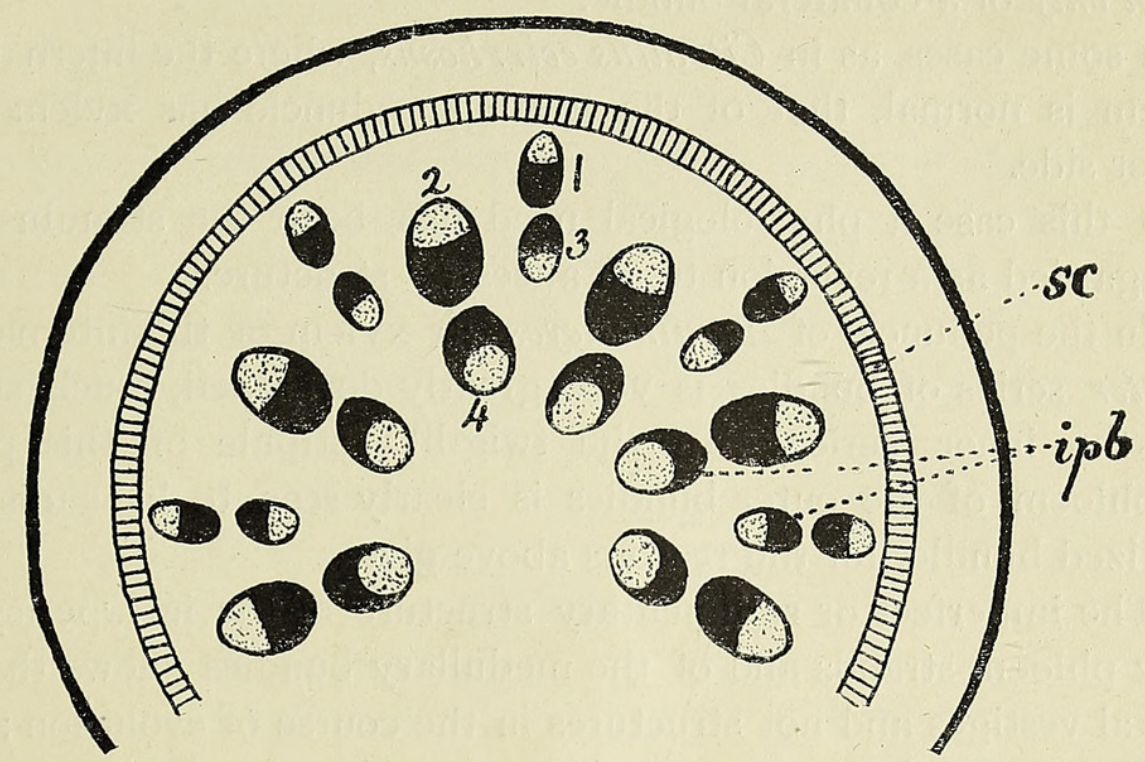

FIG. 9. Portion of transverse section of more primitive type of axis (e. g. peduncle of Ecballium), showing the inversely-orientated collateral bundles from which the internal-phloem strands have been derived $(i p b)$; a scattered system of bundles in four series. $s c_{0}=$ sclerotic ring. (Diagrammatic.)

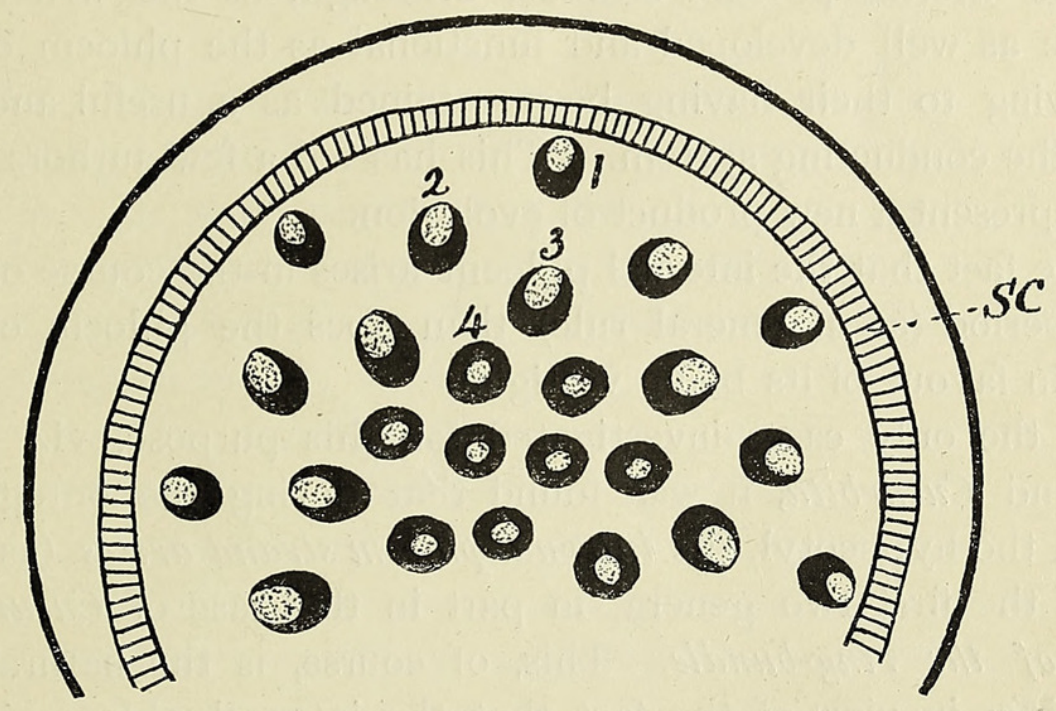

FIG. IO. Portion of transverse section of the theoretical ancestral type of stem from which that of Cucurbitaceae is presumably derived. The series of internal-phloem bundles (numbered as in Fig. 9) are here in their proper place. The innermost series are completely amphivasal. $s c_{0}=$ sclerotic ring. (Diagrammatic.)

6. The bundles or strands composing this system, on being traced upwards or downwards, either arise de novo or fuse with the internalphloem strands; in any case, the vast majority unite with the latter during some part of their course. 
7. The fact that the xylem of the medullary bundle unites with or becomes attached to the internal-phloem strand, and not with the xylem of the corresponding bundle of the cylinder, proves that the internal-phloem strand represents a distinct vascular bundle of the medullary system which has lost its xylem. No case is known in any plant of a bundle fusing with the phloem only of a collateral bundle.

8. In some cases, as in Citrullus ecirrhosus, where the internal phloem of the stem is normal, that of the fruiting peduncle has xylem attached to its outer side.

9. In this case a physiological need has been the stimulus evoking what is regarded as a reversion to an ancestral structure.

IO. In the peduncle of Acanthosicyos the xylem of the internal phloem of the outer series of bundles is very greatly developed, much surpassing that of the inner series. In the twig-like stipule of this plant the internal phloem of the outer bundles is clearly seen to be a distinct and individualized bundle, for the reasons above given.

II. The imperfect or rudimentary structure of the intrapericyclic and medullary phloem-strands and of the medullary bundles shows them all to be ancestral vestiges and not structures in the course of evolution; for such imperfectly functional structures would not have been evolved and preserved. Hence the view that the cylinder has been derived from a former scattered system of bundles is correct.

I2. The internal-phloem strands, although, as the writer considers, vestigial, are as well developed and functional as the phloem of the ringbundles, owing to their having been retained as a useful and necessary adjunct to the conducting system. This has led a few authors to suppose that they represent a new product of evolution.

13. The fact that the internal phloem arises in the course of ontogeny, at a later period (as a general rule) than does the phloem of the ringbundles, is in favour of its being vestigial.

14. In the only cases investigated for this purpose, viz. Lagenaria, Citrullus, and Cucurbita, it was found that during the ontogeny of the stem, viz. in the hypocotyl, the internal-phloem strand arises (as a whole in the case of the first two genera, in part in the case of Cucurbita) from the phloem of the ring-bundle. This, of course, is the natural and only mode of origin in view of the fact that the internal phloem is still fully functional and well developed.

I5. The internal-phloem strand (at any rate in the cases of Lagenaria and Citrullus), as it passes inwards from the phloem of the ring-bundle, revolves on its axis through an angle of $180^{\circ}$.

16. This affords the ontogenetic origin of the inversely-orientated internal-phloem bundle.

17. The morphological origin of this internal-phloem bundle is from 
(Intraxylary) Phloem in the Stems of Dicotyledons. I. 589

an amphivasal bundle, for this latter is the typical and primitive condition of medullary bundles wherever they may occur (Fig. Io).

I8. Owing to the fact that some of the outermost amphivasal medullary bundles have become approximated to the bundles of the ring to form would-be constituents of this latter, only that portion of the xylem of the original amphivasal bundle has been retained which is the most mechanically serviceable for the ring as a whole, viz. the outer portion, or that which is approximated to the xylem of the ring-bundle.

The inversely-orientated internal-phloem bundle is thus explained.

I9. In the vast majority of cases the xylem which occurs on the outer side, or other parts of the periphery, of the internal phloem is secondary in origin, i. e. is derived from a cambium. In a few cases, as in that of the outer series of bundles in the stipule and stem of Acanthosicyos, it appears to be, at least part of it, primary. The mode of origin of the xylem, whether primary or secondary, is, however, a matter of purely ontogenetic interest ; it cannot affect the morphological question as to the origin of the internal phloem, and is, in this connexion, of no importance.

20. This fact of the existence of vascular bundles replacing the internal phloem in the stem and peduncle proves that the 'bicollateral' bundle has no existence in the morphological sense, but is a purely descriptive term.

2I. The 'bicollateral' bundle of the Cucurbitaceae is a compound structure consisting of the more or less intimate association or attachment of two distinct vascular bundles, of which the innermost has lost its xylem.

22. The collateral bundles composing the two rings or series of the cylinder in this order also, in the writer's opinion, represent reduced amphivasal bundles. In some plants they are very $\mathrm{V}$-shaped, with the phloem situated between the arms of the xylem. In this feature and in that of the large size of the vessels the bundle is sometimes an exact replica of that of some Monocotyledons.

23. In most Cucurbitaceous stems there may be observed in the region outside the zone of the two main series of cylinder bundles, but within the sclerotic ring, a few extremely rudimentary phloem-strands. In Cucurbita foetidissima evident transitions between these and the bundles of the cylinder exist in the form of intermediately-situated vascular bundles.

24. This last fact shows that the external rudimentary strands represent the vestiges of a former outermost series of bundles of the cylinder.

25. The existence of the rudimentary phloem-strands just mentioned representing reduced vascular bundles helps, in some degree, to render plausible the view that the internal-phloem strands also represent reduced vascular bundles.

26. The sclerotic ring, broken up in some cases into isolated strands, marks the limit, as in Monocotyledons, of the central cylinder. 
27. The conclusion is reached that the vascular system of Cucurbitaceae represents the vestige of a former ancestral scattered system of bundles such as obtains in Monocotyledons, of which only two series or rings remain in perfect condition, the rest appearing in the form of rudimentary external phloem-strands (rarely bundles as well), 'internal-phloem' strands, and medullary bundles or phloem-strands (Figs. 8, 9, 10).

28. The sinuous contour of the bundle-ring in most Cucurbitaceae is the expression of the partial congestion of two bundle-series into onean intermediate condition between the cylindric and the scattered system.

29. Such a structure as the internal-phloem strand must be investigated both from the morphological and physiological standpoints. Its function, ontogeny, and phylogeny must all equally receive consideration.

The writer is indebted to the authorities of the Royal Gardens, Kew, for much of the material used in this study.

\section{BIBLIOGRAPHY.}

BARAnEtSky : Recherches sur les faisceaux bicollatéraux. Annales Sci. Nat., Bot., sér. 8, vol. xii, 1900).

Col: Recherches sur la disposition des faisceaux dans la tige et les feuilles de quelques Dicotylédones. Ann. Sci. Nat., Bot., sér. 8, vol. xx, 1904 .

FABER, F. C. von : Zur Entwicklungsgeschichte der bikollateralen Gefässbiindel von Cucurbita Pepo. Ber. d. deutsch. bot. Gesellsch., vol. xxii, I904.

Fischer, A. : Untersuchungen über das Siebröhrensystem der Cucurbitaceen. Berlin, i884.

Flot : Recherches anatomiques sur les Cryptogames vasculaires. Ann. Sci. Nat., Bot., sér. 7, vol. xviii, I893.

GÉRARD : Recherches sur le passage de la racine à la tige. Ann. Sci. Nat., Bot., sér. 9, vol. xi, I $88 \mathrm{I}$.

HÉraIL : Étude de la tige des Dicotylédones. Ann. Sci. Nat., Bot., sér. 7, vol. ii, I885.

Lamounette: Recherches sur l'origine morphologique du liber interne. Ann. Sci. Nat., Bot., sér. 7 , vol. xi, 1890 .

Marloth: 'Die Naras, Acanthosicyos horrida, Welw., var. namaquana; Eine monographische Studie.' Englers bot. Jahrb., vol. ix (I 888), pp. I 73-88.

Petersen : Ueber das Auftreten bicollateraler Getässbündel in verschiedenen Pflanzenfamilien und über den Werth derselben fiir die Systematik. Englers Bot. Jahrb. f. syst. Pflanzengesch. und Pflanzengeogr., vol. iii, p. 359, I882.

PitARD : Sur les faisceaux libériens tertiaires des tiges des Cucurbitacées. Actes de la Soc. Linn. de Bordeaux, sér. 6, vol. vi, ı9oI.

SANIO : Ueber endogene Gefässbündelbildung. Bot. Zeit., I 864, p. 227.

ScotT and Brebner: On Internal Phloem in the Root and Stem of Dicotyledons. Ann. Bot., vol. v, I89I.

Tieghem, van : Sur quelques points de l'anatomie des Cucurbitacées. Bull. Soc. Bot. de France, sér. 2, vol. xxix, I882.

Wallace, W.: On the Stem-structure of Actinostemma biglandulosa. Ann. Boi, vol. xiv, Dec., 1900.

WEISS, J. E. : Das markständige Gefässbuindelsystem einiger Dikotyledonen in seiner Beziehung zu den Blattspuren. Bot. Centralbl., vol. iii, I883, p. 283.

YASUDA: On the Comparative Anatomy of the Cucurbitaceae, Wild and Cultivated, in Japan. Journ. Coll. Sci., Imp. Univ., Tokyo, Japan, vol, xviii, Art. 4, I903, 


\section{$2 \mathrm{BHL}$ Biodiversity Heritage Library}

Worsdell, Wilson Crosfield. 1915. "The origin and meaning of medullary (intraxylary) phloem in the stems of dicotyledons. I. Cucurbitaceae." Annals of botany 29, 567-590. https://doi.org/10.1093/oxfordjournals.aob.a089564.

View This Item Online: https://www.biodiversitylibrary.org/item/243629

DOI: https://doi.org/10.1093/oxfordjournals.aob.a089564

Permalink: https://www.biodiversitylibrary.org/partpdf/320081

\section{Holding Institution}

Smithsonian Libraries

\section{Sponsored by}

Biodiversity Heritage Library

\section{Copyright \& Reuse}

Copyright Status: Not in copyright. The BHL knows of no copyright restrictions on this item.

This document was created from content at the Biodiversity Heritage Library, the world's largest open access digital library for biodiversity literature and archives. Visit BHL at https://www.biodiversitylibrary.org. 